\title{
Identification of mRNAs bound and regulated by human LIN28 proteins and molecular requirements for RNA recognition
}

\author{
MARKUS HAFNER, ${ }^{1,3}$ KLAAS E.A. MAX, ${ }^{1,3}$ PRADEEP BANDARU, ${ }^{1}$ PAVEL MOROZOV, ${ }^{1}$ STEFANIE GERSTBERGER, ${ }^{1}$ \\ MIGUEL BROWN, ${ }^{1}$ HENRIK MOLINA, ${ }^{2}$ and THOMAS TUSCHL ${ }^{1,4}$ \\ ${ }^{1}$ Howard Hughes Medical Institute and Laboratory for RNA Molecular Biology, The Rockefeller University, New York, New York 10065, USA \\ ${ }^{2}$ Proteomics Core Facility, The Rockefeller University, New York, New York 10065, USA
}

\begin{abstract}
Human LIN28A and LIN28B are RNA-binding proteins (RBPs) conserved in animals with important roles during development and stem cell reprogramming. We used Photoactivatable-Ribonucleoside-Enhanced Crosslinking and Immunoprecipitation (PARCLIP) in HEK293 cells and identified a largely overlapping set of $\sim 3000$ mRNAs at $\sim 9500$ sites located in the $3^{\prime}$ UTR and CDS. In vitro and in vivo, LIN28 preferentially bound single-stranded RNA containing a uridine-rich element and one or more flanking guanosines and appeared to be able to disrupt base-pairing to access these elements when embedded in predicted secondary structure. In HEK293 cells, LIN28 protein binding mildly stabilized target mRNAs and increased protein abundance. The top targets were its own mRNAs and those of other RBPs and cell cycle regulators. Alteration of LIN28 protein levels also negatively regulated the abundance of some but not all let-7 miRNA family members, indicating sequence-specific binding of let-7 precursors to LIN28 proteins and competition with cytoplasmic miRNA biogenesis factors.
\end{abstract}

Keywords: PAR-CLIP; cold-shock domain; zinc knuckle domain; miRNA processing; let-7 miRNA; snoRNA; RNA-binding proteins

\section{INTRODUCTION}

Human LIN28A and LIN28B proteins are members of an RNA-binding protein (RBP) family conserved in animals. They share $73 \%$ sequence identity and contain a unique domain composition of a cold-shock domain (CSD) and a zinc knuckle domain (ZKD) consisting of two CCHC-type zinc fingers (Supplemental Fig. 1). LIN28 was initially identified as a heterochronic gene in Caenorhabditis elegans controlling developmental events specific to the second larval stage (Ambros and Horvitz 1984; Moss et al. 1997). In mammals, LIN28 genes are also stage-specifically expressed in embryonic tissues, and to a lesser extent, in adult tissues (Yang and Moss 2003). LIN28 regulates embryonic development, myogenesis, as well as neuronal differentiation, and promotes stem-cell reprogramming (Moss et al. 1997; Polesskaya et al. 2007; Yu et al. 2007; Rybak et al. 2008; Okita et al. 2011). Knockout and ectopic expression of LIN28 in mice perturbed onset of puberty, body size, and glucose metabolism by increasing the expression and sensitivity of components of the insulin-PI3K-mTOR signaling pathway (Zhu et al. 2010,

${ }^{3}$ These two authors contributed equally to this work.

${ }^{4}$ Corresponding author

E-mail ttuschl@rockefeller.edu

Article published online ahead of print. Article and publication date are at http://www.rnajournal.org/cgi/doi/10.1261/rna.036491.112.
2011). LIN28 genes were found to act oncofetal (Chang et al. 2009; Iliopoulos et al. 2009; Balzer et al. 2010; King et al. 2011) and are highly expressed in hepatocellular and other carcinomas (West et al. 2009; Yang et al. 2010).

In murine stem cells, high expression of LIN28 coincided with low levels of let-7 miRNAs, typically expressed at late or adult stages of development, and differentiation of stem cells to neural stem cells reversed this expression pattern (Rybak et al. 2008). Transgenic expression of LIN28 in mice led to a reduction in let-7 miRNA in several neonatal and adult tissues, and transgenic induction of let-7 miRNAs reversed the regulatory effects of LIN28 overexpression (Zhu et al. 2010, 2011). These observations initially suggested direct regulatory roles of LIN28 proteins in let-7 miRNA biogenesis. However, more recently, LIN28 proteins were also found to influence gene expression during neurogliogenesis and colon cancer transformation independent of let-7 accumulation (Balzer et al. 2010). A more detailed analysis of LIN28 and let-7 miRNA expression in the same study found that in human ES cells LIN28 protein levels declined within $3 \mathrm{~d}$ of differentiation, while let-7 miRNA levels only increased post $5 \mathrm{~d}$, consistent with a less direct role of LIN28 in let-7 miRNA regulation.

LIN28 proteins were reported to be localized in the cytoplasm (Moss et al. 1997; Yang and Moss 2003; Guo et al. 
2006; Rybak et al. 2008) and associated with polysomebound mRNAs (Polesskaya et al. 2007). Among the first mRNA targets identified were IGF2, histone H2A, and several genes involved in cell cycle regulation (Polesskaya et al. 2007; $\mathrm{Xu}$ and Huang 2009; Xu et al. 2009). Recently, profiling of RNA isolated from LIN28 protein immunoprecipitates (RIP) in human embryonic stem cells and a breast cancer cell line showed enrichment of a shared set of 800 mRNAs, which included the previously identified cell cycle genes, as well as histone H2A (Peng et al. 2011; Li et al. 2012). In two new studies using HiTS-CLIP in human and murine ESCs, as well as HEK293 cells (Cho et al. 2012; Wilbert et al. 2012), more than 13,000 and 6000 transcripts were reported as targets for LIN28A, respectively. Further reporter-based analysis of a very small subset of these targets revealed that LIN28 proteins positively regulated reporter gene expression by increasing translational efficiency (Polesskaya et al. 2007; Xu and Huang 2009; Xu et al. 2009; Peng et al. 2011; Lei et al. 2012; Wilbert et al. 2012).

Multiple biochemical and structural approaches support a direct role of LIN28 in let-7 miRNA biogenesis. The addition of recombinant LIN28 protein to mammalian cell lysates inhibited processing of all members of the let-7 family by binding to their precursors (Heo et al. 2008; Newman et al. 2008; Rybak et al. 2008; Viswanathan et al. 2008). Subsequently, a G-rich element (GGAG, GAAG, or AGGG) located at the $3^{\prime}$ end of the loop region of let-7 pri- and pre-miRNA was shown to confer LIN28 protein binding and resulted either in inhibition of DROSHA (Newman et al. 2008) or DICER1 RNase III processing (Hagan et al. 2009; Heo et al. 2009; Lehrbach et al. 2009). A GGAGA motif was also reported to be present in $28 \%$ of the LIN28A-HiTS-CLIP defined mRNA-binding sites and was the most significantly enriched sequence element (Wilbert et al. 2012). Co-crystals of mouse or Xenopus LIN28 proteins with fragments of Xenopus prelet-7f miRNA showed that both, CSD and ZKD, interacted with single-stranded regions within the pre-let-7 loop, corresponding to a pyrimidine-rich segment and a GGAG motif, respectively (Nam et al. 2011; Mayr et al. 2012). These interactions were similar to those previously observed for bacterial CSDs, which bound single-stranded pyrimidine-rich sequences with very few nucleobase-specific contacts (Phadtare and Inouye 1999; Max et al. 2006). The LIN28 ZKD contacts isolated guanosines located in the loop of an HIV RNA hairpin (De Guzman et al. 1998) resembling RNA interactions of the ZKD of HIV protein NP7, which is $50 \%$ sequence similar.

It was also shown that LIN28 prevented cytoplasmic miRNA maturation through stimulation of cytoplasmic decay of pre-let-7 by recruiting the terminal uridilyl transferase ZCCHC11/TUT4, catalyzing the addition of a polyuridine tail and thereby tagging RNA for degradation (Heo et al. 2008, 2009; Hagan et al. 2009; Lehrbach et al. 2009). Considering the predominantly cytoplasmic localization reported for LIN28 protein (Moss et al. 1997; Guo et al. 2006;
Polesskaya et al. 2007), it was difficult to reconcile inhibition of nuclear DROSHA-processing of pri-miRNAs (Lee et al. 2002). However, a recent study unexpectedly reported localization of human LIN28B predominantly in the nucleus and supported its previously reported role of interference with DROSHA-mediated pri-let-7 processing (Piskounova et al. 2011). Overall, these apparently conflicting models regarding LIN28 localization and function in let-7 biogenesis, as well as recent evidence for parallel expression of LIN28 and let-7 genes, warranted further analyses of the role of LIN28 and its target RNAs.

In order to identify the direct RNA targets and precise binding sites of LIN28 proteins in vivo, we applied Photoactivatable-Ribonucleoside-Enhanced Crosslinking and Immunoprecipitation (PAR-CLIP) in HEK293 cells using 4-thiouridine. The method is known for its precision in identification of binding sites resulting from T-to-C sequence conversions upon RNA-protein crosslinking. We observed that LIN28A and LIN28B proteins were largely localized to the cytoplasm and predominantly crosslinked to mRNAs. Both proteins bound to a largely overlapping set of $\sim 9500$ sites located in the CDS and $3^{\prime}$ UTR of 3000 mRNAs. PAR-CLIP binding regions contained uridine-rich segments flanked by one or more guanosines, and RNA-protein interaction was further confirmed by gel mobility-shift assays. Overexpression and knockdown of LIN28 followed by global profiling of mRNA and protein abundance showed that LIN28 protein stabilized its target RNAs with a concomitant increase in protein levels. The enrichment of many other mRNA-binding proteins (mRBPs) among the large number of mRNA targets suggests that LIN28 has a broad role in post-transcriptional regulation of many genes, thereby contributing to development and oncogenesis.

\section{RESULTS}

\section{LIN28A and B are predominantly cytoplasmic mRNA-binding proteins}

We generated stable HEK293 cell lines for doxycycline-inducible expression of FLAG/HA-tagged human LIN28A and LIN28B (Spitzer et al. 2011). Recombinant human LIN28A and LIN28B proteins were obtained by bacterial expression (Supplemental Fig. 1). These reagents were used for validation of commercial antibodies suitable for Western blotting and discriminating between LIN28A and LIN28B (Supplemental Fig. 1). Endogenous LIN28A but not LIN28B protein was expressed in IGROV1, whereas endogenous LIN28B but not LIN28A protein was present in K562 and HEK293 (Fig. 1A; Supplemental Fig. 2). Western blot analysis of nuclear and cytoplasmic fractions (Dignam et al. 1983) of K562 and FLAG/ HA-tagged LIN28B-expressing HEK293 cells found that endogenous and tagged LIN28B proteins were present to $70 \%$ in the cytoplasm (Fig. 1A). LIN28A protein endogenously expressed in IGROV1 cells yielded similar distributions, but the 


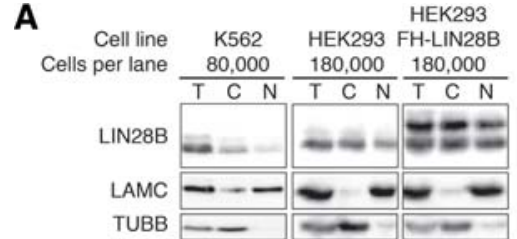

B

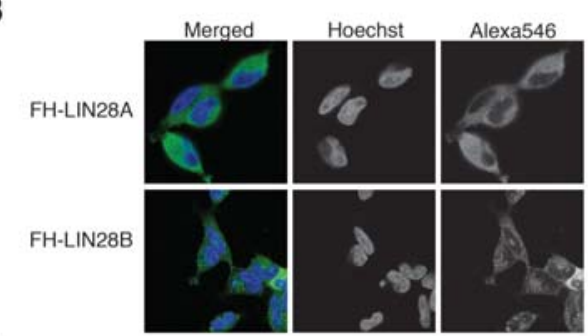

$\mathbf{F}$

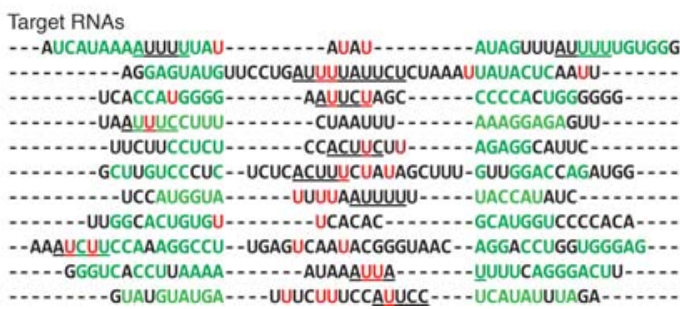

C

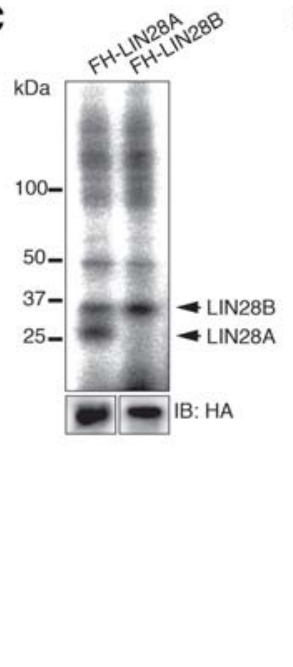

D

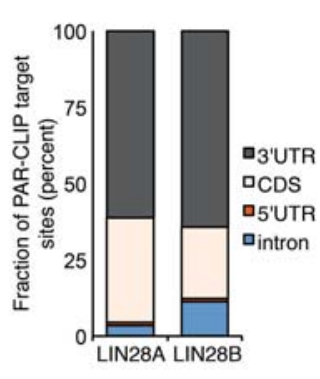

$\mathbf{E}$

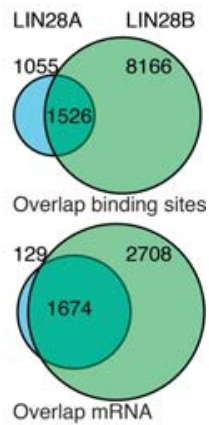

$\begin{array}{llll} & \begin{array}{l}\text { Number } \\ \text { of crosslinked } \\ \text { reads in site }\end{array} & \begin{array}{l}\text { Total number } \\ \text { of crosslinked } \\ \text { reads }\end{array} & \begin{array}{l}\text { Total number } \\ \text { Transcript }\end{array} \\ \text { HMGA2 } & 280 & 346 & 16 \\ \text { MKLN1 } & 164 & 216 & 6 \\ \text { SLC1A5 } & 39 & 110 & 10 \\ \text { *HECA } & 26 & 144 & 6 \\ \text { CCND2 } & 25 & 188 & 17 \\ \text { IGF2BP1 } & 24 & 225 & 23 \\ \text { *PARPBP } & 18 & 21 & 2 \\ \text { CLASP1 } & 11 & 54 & 9 \\ \text { LIN28B } & 9 & 573 & 19 \\ \text { VMA21 } & 6 & 217 & 13 \\ \text { *CBX5 } & 6 & 948 & 40\end{array}$

FIGURE 1. LIN28A and LIN28B are cytoplasmic mRNA-binding proteins. (A) Western blot analysis of nucleocytoplasmic fractions prepared from indicated cell lines. Total cell lysate $(\mathrm{T})$, cytoplasmic extract $(\mathrm{C})$, and nuclear extract $(\mathrm{N})$ corresponding to the indicated number of cells were resolved on a $4 \%-12 \%$ SDS gel and then probed by Western blotting using antibodies targeting LIN28A and LIN28B. Antibodies for TUBB and LAMC were used to control for the purity of the cytoplasmic and nuclear fractions, respectively. (B) Immunofluorescence staining of FLAG epitope in stable HEK293 cells expressing FLAG/HA-LIN28A (top) and FLAG/HA-LIN28B (bottom). (C) Phosphorimage of an SDS-PAGE fractionating PARCLIP immunoprecipitate from stable HEK293 cells inducibly overexpressing FLAG/HA-tagged LIN28A and LIN28B. The crosslinked RNALIN28A and LIN28B complexes are indicated. Anti-HA Western blotting control for expression and loading is shown at the bottom. $(D)$ Distribution of PAR-CLIP binding sites on mRNAs as identified by PARalyzer. (E) Overlap of binding sites for LIN28A and LIN28B at the nucleotide level (top) and at the transcript level (bottom). (F) Representative mRNA target sites identified by PAR-CLIP and shared by LIN28A and LIN28B. Nucleotides colored in green are predicted by RNAfold to be paired, uridines colored in red showed the T-to-C mutation characteristic of crosslinking. Underlined sequence stretches contained the AYYHY polypyrimidine stretch identified by motif analysis. The number of crosslinked sequence reads per region displayed the total number of crosslinked sequence reads across the entire mRNA, and the total number of LIN28B PARCLIP groups are listed. $\left.{ }^{*}\right)$ Sequences that were selected for in vitro assays.

signals were too weak to be accurately quantified (data not shown). The nuclear portion of LIN28 proteins determined by biochemical fractionation may be overestimated due to incomplete removal of proteins from the outer nuclear membrane (Rosner and Hengstschläger 2008). Therefore, we also monitored FLAG/HA-tagged LIN28A and LIN28B protein in HEK293 cells using immunofluorescence and observed a predominantly cytoplasmic localization. Furthermore, we noticed a weak nucleolar-like signal for LIN28B, but not LIN28A (Fig. 1B).

Using quantitative Western blotting with recombinant protein as a standard, we determined cellular LIN28B protein copy numbers. We found $\sim 650,000$ and $\sim 160,000$ molecules per cell in K562 and parental HEK293 lines, respectively. In doxycycline-induced stable FLAG/HA-tagged LIN28B HEK293 cells a total of $\sim 580,000$ LIN28B protein molecules were detected at $16 \mathrm{~h}$ post-induction (Supplemental Fig. 2).
RNA-binding sites for LIN28A and LIN28B proteins were determined by 4 -thiouridine (4SU) PAR-CLIP using either FLAG/HA-tagged LIN28A or LIN28B HEK293 cells (Hafner et al. 2010a,b). Phosphorimaging of the ribonuclease-treated, immunoprecipitated, and radiolabeled RNP complexes resolved by SDS-PAGE revealed major bands at $\sim 30$ and $\sim 36 \mathrm{kDa}$, corresponding to FLAG/HA-tagged LIN28A and LIN28B proteins, respectively (Fig. 1C). Three minor crosslinked products migrating at $\sim 50,100$, and $125 \mathrm{kDa}$ presumably represent other abundant RBPs binding near LIN28 sites, or multiple LIN28 proteins crosslinked to single target RNA segments. The RNA segments crosslinked to LIN28A and LIN28B proteins were converted into small RNA cDNA libraries and Illumina-sequenced. Sequence reads were aligned to the genome and reference transcriptome (Supplemental Table 1) and grouped by PARalyzer (Corcoran et al. 2011) to identify segments of RNA that 
represented peaks of T-to-C conversion, yielding $\sim 30,000$ groups each for LIN28A and LIN28B (Supplemental Table 2; https://rnaworld.rockefeller.edu/lin28). The majority of the grouped reads for LIN28A and LIN28B (76\% and 44\%) were annotated as rRNA, but showed few T-to-C conversions $(<15 \%)$ and represented mainly noncrosslinked background. A total of $7 \%$ and $24 \%$ of grouped reads from LIN28A and LIN28B, respectively, were annotated as mRNA and showed a T-to-C conversion of $>50 \%$ (Supplemental Table 1 ).

We considered groups of sequence reads as binding sites if they (1) passed thresholds of $\geq 0.25$ for T-to-C conversion frequency, (2) contained more than five reads with T-to-C conversion, and (3) showed at least two independent conversions. We obtained $\sim 3000$ binding sites of an average length of $30 \mathrm{nt}$, of which $\sim 2500$ distributed to 1800 mRNAs for LIN28A, and $\sim 11,400$ binding sites, of which $~ 9500$ distributed to $\sim 3800$ mRNAs for LIN28B (Supplemental Tables 1, 3). More than $90 \%$ of the mRNA annotated PARalyzer binding sites were located in exonic regions, mainly in the $3^{\prime}$ UTR (>65\%), but also in the CDS (Fig. 1D), analogous to distributions seen for other cytoplasmic RBPs, such as members of the EIF2C/AGO or IGF2BP families (Hafner et al. 2010b). LIN28A and LIN28B protein bound largely the same target sites, as indicated by a $60 \%$ overlap of binding sites derived from the smaller LIN28A data set and compared with the larger LIN28B data set (Fig. 1E).

\section{LIN28A and LIN28B proteins also crosslink to snoRNAs}

LIN28 was previously shown to specifically inhibit processing of pri- and pre-let-7 miRNA-hairpins in vitro by direct binding to their stem-loop structure. To assess whether let-7derived RNAs showed crosslinking evidence, we aligned adapter-trimmed sequence reads $\geq 20 \mathrm{nt}$ from the sequenced libraries directly to pre-miRNAs of the let- 7 family, their cistronic members of the miR-99/100 and miR-125 families, and for reference to sequence-unrelated miR-19b, miR-103, and miR-106b (Supplemental Fig. 3; Supplemental Table 4). Between $5 \%$ and $10 \%$ of the best-matched reads to individual let-7 precursors contained T-to- $\mathrm{C}$ conversions compared with $1 \%$ to $10 \%$ for the sequence unrelated miRNA precursors. While this T-to-C conversion frequency is well below our cut-off for scoring crosslinking, between $27 \%$ and $83 \%$ of the mismatched positions that mapped to let$7 \mathrm{a}$, let-7b, let7d, and let-7f, from LIN28A and LIN28B libraries, respectively, were T-to-C transitions. For comparison, mutations in reads corresponding to miR-99a, miR99b, miR-100, miR-125a, and miR-125b, cistronically expressed with let-7a-2, let-7c, and let-7e, were only to $0 \%-$ $10 \%$ T-to-C (Supplemental Table 4). This analysis supports direct interactions of LIN28 proteins with let-7 miRNAs or its precursors, but the crosslinking evidence was much weaker compared with T-to-C transition frequencies observed for miRNAs in EIF2C/AGO PAR-CLIP experiments (Hafner et al. 2010b) and may indicate that only a small amount of let-7 precursors was available for binding, or a small fraction of let-7 precursor RNAs was occupied by LIN28 proteins in HEK293 cells relative to its mRNA targets.

LIN28A and LIN28B also crosslinked to a subset of expressed snoRNAs and/or their precursors, consistent with the nucleolar signal of LIN28B (and a weaker signal for LIN28A) seen by immunofluorescence (Supplemental Fig. 4). The crosslinked snoRNAs belong exclusively to box C/D snoRNAs, which form hairpin structures with 4-5-bp stems involving the $5^{\prime}$ and $3^{\prime}$ ends. The crosslinking sites were located at the $5^{\prime}$ and $3^{\prime}$ ends of the snoRNAs and reads with T-to-C conversions often extended into the precursor regions, indicating that LIN28 binding may also influence snoRNA biogenesis. However, only $0.1 \%$ of all crosslinked reads were annotated as snoRNAs, similar to the low abundance of miRNAs, suggesting that these nuclear RNAs or their precursors, when compared with mRNAs, were not major targets of LIN28 proteins.

\section{Computational characterization of LIN28 protein-binding sites}

We applied a Gibbs motif finding algorithm (Ng and Keich 2008 ) to the top 500 crosslinked binding sites with an average length of $30 \mathrm{nt}$ based on T-to-C frequency and identified a short degenerated pyrimidine-rich motif of the type AYYHY $(\mathrm{Y}=\mathrm{U}, \mathrm{C}$ and $\mathrm{H}=\mathrm{A}, \mathrm{C}, \mathrm{U})$. This motif was present in $93 \%$ of all LIN28B binding sites, while GGAG, which was reported to occur in $28 \%$ of HiTS-CLIP-defined binding sites (Wilbert et al. 2012), was only present at $2 \%$ in our narrowly defined sites. Nevertheless, we noticed that LIN28 protein binding sites were comparatively G-rich ( $15 \% \mathrm{G})$, given that G-containing segments are normally trimmed by RNase T1 during PAR-CLIP unless these guanosines are protected from cleavage by direct binding of the RBP or by stable RNA secondary structure (Kishore et al. 2011).

To assess a possible contribution of guanosines to RNA secondary structure, we searched for structural elements as additional determinants of binding, analogous to the short stems recognized in the snoRNA-binding sites, and to the reported pre-miRNA stem-loops bound in vitro. When RNAfold (Hofacker 2003) was used to predict base-pairing within top mRNA groups, we found that many LIN28 protein binding sites folded into stem-loop structures with 420-nt loops and stems ranging between 4 and 15 bp (Fig. $1 F)$. Considering the broad variation in loop size and stem length, and without further formal statistical analysis, the secondary structure pattern likely appeared by chance, given the average $15 \% \mathrm{G}$ composition at binding sites.

\section{Biochemical characterization of LIN28 protein-binding sites}

Next, we performed electrophoretic mobility shift assays (EMSAs) using recombinant full-length LIN28A and 
LIN28B proteins (Supplemental Fig. 1) and synthetic RNAs corresponding to binding sites identified by PAR-CLIP. Both proteins bound RNA with similar affinity and specificity (Supplemental Fig. 5). We therefore performed the majority of EMSAs using recombinant LIN28A, which was also less prone to aggregation. We selected three binding sites that we identified within the $3^{\prime}$ UTRs of HECA, PARPBP, and CBX5, each predicted to form stems of $6 \mathrm{bp}$ and containing pyrimidine-rich loops of 7-14 nt (Fig. 2A). While the 26- and 23-nt RNAs corresponding to CBX5 and PARPBP had dissociation constants $\left(K_{\mathrm{D}}\right)$ of $\leq 10 \mathrm{nM}$, the 19-nt RNA corresponding to HECA bound with less affinity and a $K_{\mathrm{D}}<100 \mathrm{nM}$. Shortening the RNAs to their respective 9- to 16-nt loop regions abolished gel-shift with LIN28A protein, indicating that either the length of the RNA, or the stem, or a sequence element within the stem, contributed to binding.

To isolate the contribution of single-stranded RNA (ssRNA) and double-stranded RNA (dsRNA) segments to binding, we tested several synthetic 18-nt ssRNAs composed of dinucleotide repeats as well as synthetic dsRNAs formed upon annealing of 18-nt complementary dinucleotide repeat
RNAs (Fig. 2B). Of the ssRNAs, LIN28A bound to (AG) ${ }_{9}$ and $(\mathrm{GU})_{9}$ with a $K_{\mathrm{D}}$ of $<10 \mathrm{nM}$, and $(\mathrm{U})_{18}$ with a $K_{\mathrm{D}}$ of $\sim 50 \mathrm{nM}$, while there was no detectable interaction with $(\mathrm{C})_{18},(\mathrm{AC})_{9}$, and $(\mathrm{UC})_{9}$. Duplexes of self-complementary $(\mathrm{AU})_{9}$ and $(\mathrm{GC})_{9}$, as well as $(\mathrm{GU})_{9}-(\mathrm{AC})_{9}$, and $(\mathrm{AG})_{9}-(\mathrm{UC})_{9}$ were bound with reduced affinities compared with ssRNA, and the $K_{\mathrm{D}}$ values ranged from $100 \mathrm{nM}$ to $1 \mu \mathrm{M}$ (Fig. 2C). Together with the binding experiments for LIN28A proteins using natural target sequences, this showed that (1) $(\mathrm{U})_{18},(\mathrm{GU})_{9}$, and $(\mathrm{AG})_{9}$ ssRNAs were optimal ligands, (2) ssRNA sequences $\geq 18$ nt were capable of high-affinity binding, and (3) dsRNA were either bound less efficient than ssRNA or that a fraction of dsRNA was unwound and the resulting ssRNA bound by LIN28 proteins.

Substitution of a single $\mathrm{C}$ with $\mathrm{G}$ in the otherwise inert single-stranded $(\mathrm{AC})_{9}$ converted it to an RNA ligand with a $K_{\mathrm{D}}$ of $\sim 250 \mathrm{nM}$ (Fig. 2D). Further placement of one or two GAG elements into $(\mathrm{AC})_{9}$ increased its affinity, yielding $K_{\mathrm{D}}$ values of 50 and $5 \mathrm{nM}$, respectively (Fig. $2 \mathrm{D}$ ). The RNAbinding affinity was also moderately increased by placement of two UAU elements into (AC) ${ }_{9}$ (Fig. 2D). Considering that
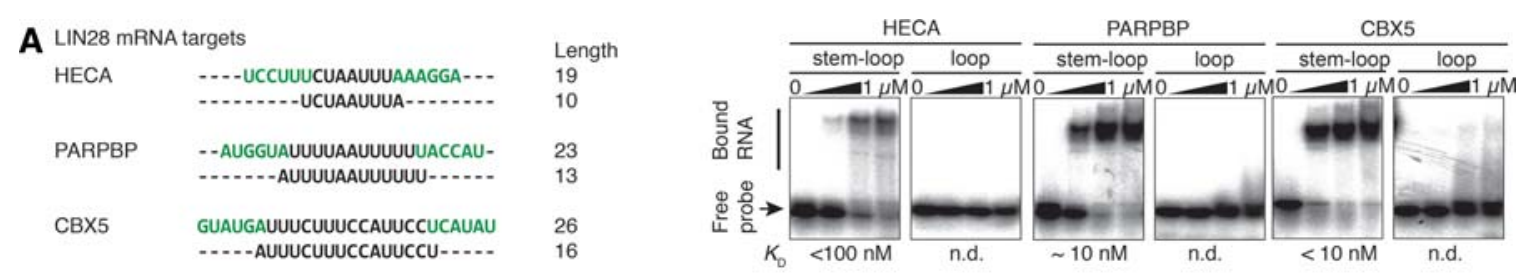

B
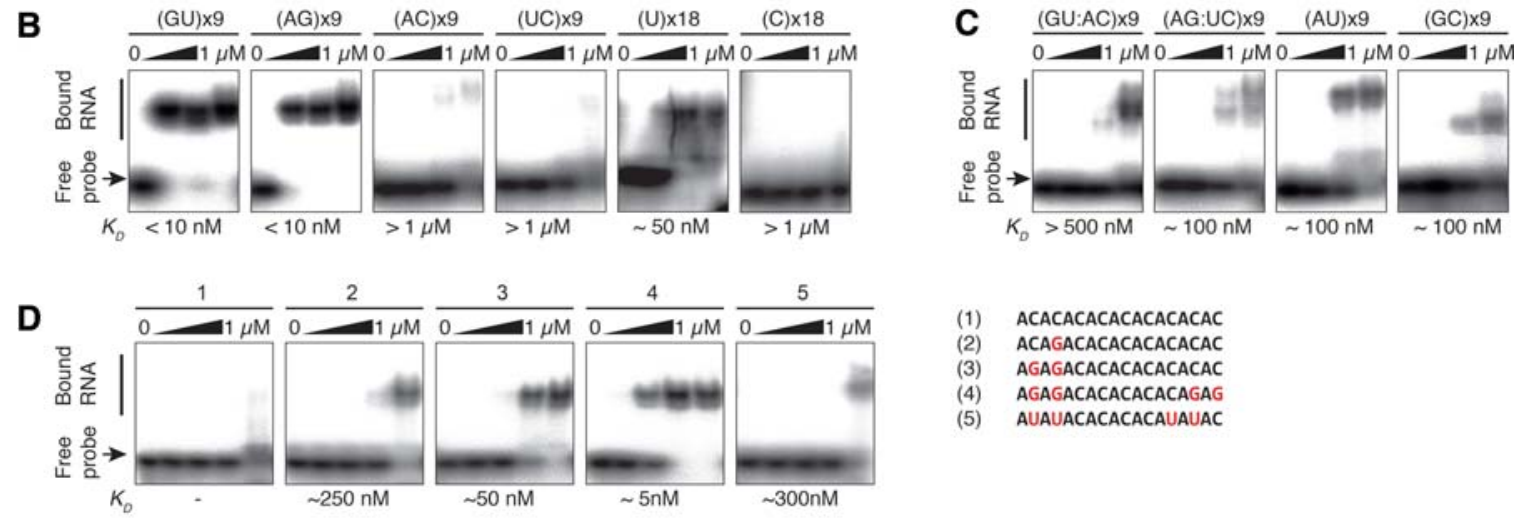

E Pre-let-7a-1 sequences

(1) UGGGAUGAGGUAGUAGGUUGUAUAGUUUUAGGGUCACACCCACCACUGGGAGAUAACUAUACAAUCUACUGUCUUUCCUA (2)

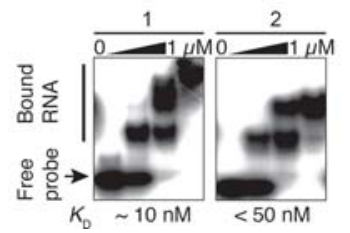

FIGURE 2. LIN28 proteins binds PAR-CLIP targets and single-stranded RNA in electrophoretic mobility shift assays (EMSA). (A) Synthetic RNAs representing the stem-loop and the loop of LIN28 mRNA targets were radiolabeled, incubated with 0, 10, 100, and $1000 \mathrm{nM}$ recombinant LIN28A, and separated on a 5\% native polyacrylamide gel. The RNA sequences are shown to the left, with nucleotides predicted to pair marked in green. The estimated $K_{\mathrm{D}}$ value of the interaction is indicated. (B) Same as in $A$, with sequences representing single-stranded RNA. (C) Same as in $A$, with sequences from $B$ that were hybridized to each other to yield double-stranded RNA. (D) Same as in $A$ using the nonbinding 18-nt sequence (AC) and substituting a number of cytidines for guanosines (panels 2-4) or uridines (panel 5). LIN28A dilution series was 0, 1, 10, 100, and 1000 nM. (E) Same as in $A$, with sequences derived from human pre-let-7a-1. 
(U) ${ }_{18}$ bound with a $K_{\mathrm{D}}$ of $\sim 50 \mathrm{nM}$ (Fig. 2D), these experiments document contribution of $U$, as well as $G$ residues to LIN28 protein binding. Furthermore, given the modest sequence change from GAG to CAC within the oligo(CA) context, it is unlikely that increased affinity is the result of an induction of a stable secondary structure.

To reconcile our binding studies with previous binding studies using pre-let-7 hairpin RNAs in EMSAs (Piskounova et al. 2008, 2011; Nam et al. 2011), we tested pre-let-7a-1 substrates and found, similar to the earlier reports using pre-let$7 \mathrm{e}$ and pre-let- $7 \mathrm{~g}$, strong binding with a $K_{\mathrm{D}} \sim 10 \mathrm{nM}$ (Fig. $2 \mathrm{E})$. However, in contrast to the single-size bands in EMSAs obtained for our 20- to 30-nt RNA targets, let-7a-1 premiRNA appeared in multiple bands, indicating the presence of up to three LIN28A molecules per pre-let-7a-1 RNA. Shortening of the pre-let-7a-1 stem to $6 \mathrm{bp}$ did not decrease affinity, but did reduce the number of bound LIN28 protein molecules to two. Given the preference for binding to ssRNA and the location of two consensus binding sites within and near the loop of the miRNA precursor, it is conceivable that binding of the first LIN28 protein weakens the stem and further exposes U-rich sequence and G elements for binding of subsequent LIN28 proteins along the prelet-7a-1 RNA.

To further evaluate the influence of predicted stems to binding of loop regions by LIN28 protein, we selected the PAR-CLIP binding site located in the $3^{\prime}$ UTR of CBX5 (Fig. 2A). This site contained a 14-nt loop with eight uridines and no guanosines, and a 6-bp stem with two guanosines. Shortening the stem from 6 to 4 to 2 bp increased $K_{\mathrm{D}}$ values from $<10 \mathrm{nM}$ to $\sim 50$ and $100 \mathrm{nM}$, respectively, while deletion of the entire stem led to a complete loss of binding (Fig. 3, panels 1-4). While these results could be interpreted to support the involvement of a stem structure, they may also indicate a sequence or length requirement for binding. Substituting all eight uridines in the loop for cytidines while maintaining the 6-bp stem reduced the affinity to $\sim 100 \mathrm{nM}$ (Fig. 3, panel 5), documenting the contribution of uridines to LIN28 protein binding. Shortening of the loop to $6 \mathrm{nt}$, thereby removing four of the eight uridines, or removal of the 6-nt $5^{\prime}$ arm of the stem containing the only two guanosines, also reduced affinity to $100 \mathrm{nM}$, whereas removal of the 6-nt $3^{\prime}$ arm devoid of guanosines of the stem had a lesser effect (Fig. 3, panels 6-8). This apparent contribution of guanosines to binding affinity was further explored by disruption of base-pairing of the stem by changing its sequence, yet retaining guanosines. Indeed, this change did not influence binding (Fig. 3, panel 9), and furthermore, compensatory changes that restored base-pairing and retained guanosines also had no effect on binding (Fig. 3, panel 10). Extending the original 6-bp stem to $12 \mathrm{bp}$, including additional guanosines and a triple-uridine element, showed no change in affinity; however, more than one LIN28 protein molecule was now able to bind (Fig. 3, panel 11). Shortening of the loop of this 12-bp stem to $6 \mathrm{nt}$, analogous to the deletion above (Fig. 3, panel 8) retained high binding affinity as well as binding to two LIN28 protein molecules (Fig. 3, panel 12). We interpret these results in support of LIN28 protein binding to single-stranded RNA regions, as well as its ability to recognize sequence motifs comprised within predicted secondary structure presumably facilitating unwinding target RNAs and capturing dynamic single-stranded conformation. Nucleation of LIN28 protein binding likely occurs at loop regions by one of its RNA-binding domains, followed by fraying of the stem as the protein captures additional binding sites. In a broader sense, LIN28 proteins match the definition of an RNA chaperone, affecting and reorganizing RNA secondary structure.

\section{LIN28 protein binding positively regulates target mRNAs}

In order to gain insight into possible regulatory pathways controlled by LIN28, we examined the top 3000 transcripts ranked by T-to-C frequency using GO analysis (Huang et al. 2009a,b) and found high enrichment (DAVID enrichment score between 10 and 40) for several functional categories among LIN28 targets. At the top were genes involved in
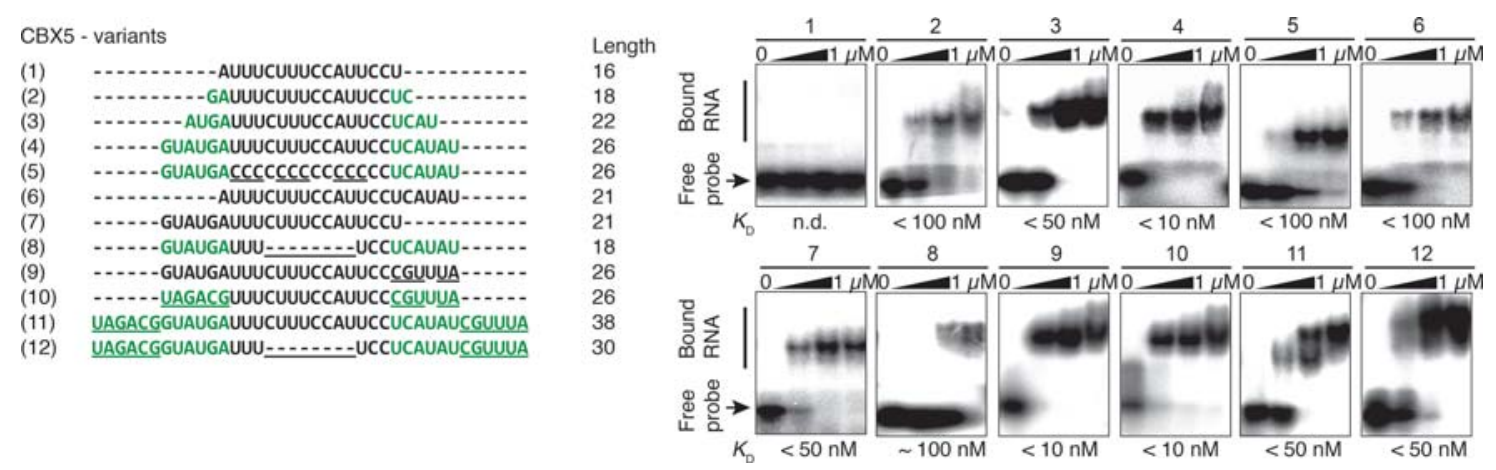

FIGURE 3. LIN28 does not require the stem of stem-loop structure for binding. EMSAs for synthetic RNAs derived from a LIN28 target site on the $3^{\prime}$ UTR of CBX5 were performed as in Figure 2. The RNA sequences are shown to the left, with nucleotides predicted to pair marked in green. The estimated $K_{\mathrm{D}}$ value of the interaction is indicated. 
nuclear processes, 455 targets among 1450 genes in the category $\left(P=4.4 \times 10^{-56}\right)$ including, in particular, chromatin components, 66 of $200\left(P=3.3 \times 10^{-9}\right)$, and transcriptional regulators, 472 of $2026\left(P=2.7 \times 10^{-23}\right)$. Furthermore, cell cycle-related genes, 236 of $776\left(P=1.3 \times 10^{-21}\right)$, RNA splicing factors, 111 of $284\left(P=5.9 \times 10^{-19}\right)$, and RBPs, 193 of $540\left(P=7.8 \times 10^{-32}\right)$ were well enriched (Supplemental Table 5). The influence on cell division and gene regulation is consistent with the role of LIN28 in stem-cell reprogramming and oncogenesis.

We next recorded mRNA profiles in FLAG/HA-LIN28Binduced and uninduced HEK293 cell lines, as well as uninduced HEK293 cells after siRNA knockdown of endogenous LIN28B, to study the regulatory effect of LIN28B protein binding on its target mRNAs (Fig. 4A,B; Supplemental Table 6). Cumulative distribution analysis of mRNA profiles of FLAG/HA-LIN28B overexpression increased target mRNA abundance compared with endogenous LIN28B knockdown by a small value of $0.8 \%(P=0.001)$, indicating that LIN28B protein stabilizes regulated targets.
We also quantified abundance for $\sim 3500$ proteins using a SILAC approach (Supplemental Table 7; Supplemental Fig. 6 for scheme) and compared target protein levels in cells induced for expression of FLAG/HA-LIN28B vs. siRNA knockdown, both after $72 \mathrm{~h}$. The cumulative distribution in protein abundance for the $\sim 1700$ detected proteins corresponding to LIN28 PAR-CLIP targets did not change in a statistically significant manner, which may mirror the small differences in mRNA abundance overlaid by the more technically challenging quantification of mass spec data.

We nevertheless used the proteome data for a refinement of our analysis, selecting target RNAs for which the encoded protein was detected by mass spectrometry. We binned target transcripts into three groups (500, 500, and 732 members) by descending $\mathrm{T}$-to- $\mathrm{C}$ frequency, which is a composite measure for affinity and target abundance (Hafner et al. 2010b). The bin containing the top 500 transcripts showed the strongest LIN28B-dependent mRNA stabilization (Fig. 4B). GO-analysis for this subset showed the highest enrichment for RBPs $(P$ $\left.=1.2 \times 10^{-32}\right)$, representing 93 proteins, of which 35 contain
A

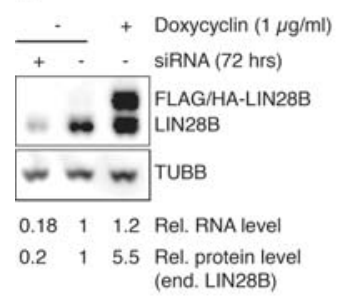

D

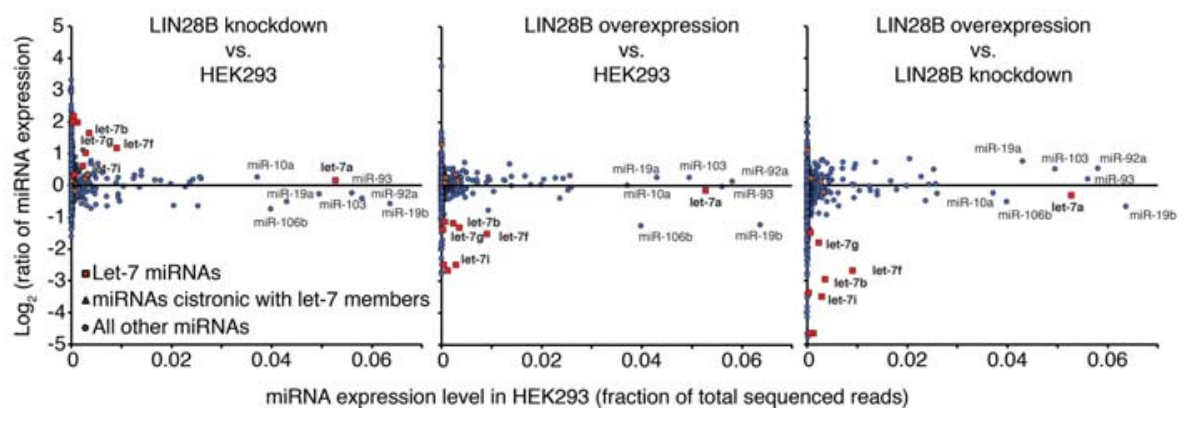

FIGURE 4. LIN28 binding increases target mRNA and protein abundance. ( $A$ ) Western blot using antibodies against endogenous LIN28B after knockdown, mock transfection, and induced expression of FLAG/HA-tagged LIN28B. Sample loading was controlled using an anti-TUBB antibody. Signals for LIN28B and TUBB were quantified, and relative LIN28B protein levels are indicated. LIN28B mRNA levels were determined using Affymetrix HGU133 whole-genome microarrays. (B) Increase in LIN28 target mRNA abundance. Changes in transcript stability from LIN28B overexpression relative to LIN28B knockdown were inferred from microarray analysis. Shown are the distributions of changes upon four transcripts that were divided into the indicated bins based on the presence of PAR-CLIP binding sites, detection of protein in mass spectrometric assays, and the number of crosslinked sequence reads. $\left.{ }^{*}\right) P<0.05,\left({ }^{* *}\right) P<0.01,\left({ }^{* * *}\right) P<0.001$ in Student's $t$-test, two-tailed. $(C)$ Changes in protein levels after LIN28B overexpression and knockdown were determined by SILAC approaches. $\left({ }^{*}\right) P<0.05$. Proteins were grouped according to the same criteria as in $B$. ( $D$ ) Changes in miRNA profiles of HEK293 cells after LIN28B knockdown (left) and overexpression (middle) were recorded by small RNA cDNA library sequencing. miRNAs were sorted according to expression in uninduced HEK293 cells. Top eight mature miRNAs are indicated and members of the let-7 miRNA family are shown as red squares and miRNAs coexpressed with let-7 miRNAs in transcriptional units or cistrons are shown as orange triangles. (Right) The comparison of miRNA levels after knockdown and overexpression of LIN28B. 
RRM-domains $\left(P=2.5 \times 10^{-16}\right)$ (see Supplemental Table 5). These 93 RBPs are further subclassified as nuclear (58), cytoplasmic (17), and shuttling between nucleus and cytoplasm (18). Cumulative distribution analysis of the change in protein levels in the bin of 500 top RNA targets including the 93 RBPs now revealed a LIN28-dependent increase in protein levels $(P=0.053$ for the top 500 targets and $P=0.017$ for 93 top RBPs) mirroring the stabilizing effect seen at the mRNA level (Fig. 4C; Supplemental Table 7). Together, our analysis suggests that LIN28 proteins may indirectly coordinate nuclear RNA processing and nucleocytoplasmic mRNA transport events via their numerous RBP targets.

Because many RNA-binding proteins regulate their own synthesis, we examined LIN28B mRNA and protein levels more closely. After $72 \mathrm{~h}$ of induction of expression of FLAG/HA-LIN28B, the levels of endogenous LIN28B protein increased fivefold (Fig. 4A). LIN28B binds to its own message at seven positions, with the most prominent site located in the CDS, 200 nt from the start codon (Supplemental Fig. $7)$. In contrast, analysis of the mRNA levels of endogenous LIN28B by RT-qPCR with primers placed in its $3^{\prime}$ UTR, absent from the LIN28B transgene, only detected a corresponding 1.5-fold increase in abundance, suggesting a role for LIN28B protein binding in autoregulation beside its own mRNA stabilization, possibly affecting translation initiation.

\section{LIN28 knockdown and overexpression in HEK293 and its effect on miRNA abundance}

LIN28 protein has been considered a direct regulator of let-7 miRNA abundance (Thornton and Gregory 2012). We determined changes in miRNA abundance by barcoded small RNA cDNA library sequencing after expressing FLAG/HAtagged LIN28B for $72 \mathrm{~h}$, after mock transfection, and after LIN28B knockdown $72 \mathrm{~h}$ post-LIN28B siRNA transfection (Fig. 4D; Supplemental Table 8). The let-7 miRNA family represented $\sim 7 \%$ of the total miRNA-annotated reads and represented the third most abundantly expressed miRNA se- quence family in HEK293 cells. Among all let-7 family members, $70 \%$ of reads originated from let-7a-1 and let-7a-3, while let-7a-2 was poorly expressed based on low read counts for its star sequence as well as its cistronic neighbors miR100 and miR-125b-1. LIN28B knockdown increased let-7a miRNA abundance by only 1.1-fold compared with uninduced cells, while let-7b, let-7c, let-7d, let-7f, let-7g, let-7i, and miR-98, increased 1.3- to fourfold, but overall did not contribute much to the let-7a-dominated miRNA family abundance. Conversely, LIN28B overexpression resulted in a 1.1-fold decrease of let-7a, and a two- to sixfold decrease for let-7c, let-7b, let-7f, let-7g, let-7i, and miR-98 (Fig. 4D).

Let-7c, let-7e, and let-7g are organized in cistrons with sequence-unrelated miRNAs (let-7c together with miR-99a and miR-125b-2, let-7e together with miR-99b and miR$125 \mathrm{a}$, and let-7g together with miR-135a-1). The abundance of these neighboring miRNAs was unaffected by LIN28B knockdown or overexpression, indicating that let-7 regulation by LIN28B was indeed specific and post-transcriptional. The extent of regulation of individual let-7 members by LIN28B relates to the sequence composition of the precursor stem-loop. Pre-let-7b, pre-let-7d, pre-let-7g, pre-let-7i, prelet-7f-1, and pre-miR-98 share longer, uridine-rich loops, compared with pre-let-7a, pre-let-7c, pre-let-7e, and prelet-7f-2 (Fig. 5), and were also more regulated.

\section{DISCUSSION}

\section{LIN28 proteins predominantly bind mature mRNAs}

Considering that the majority of grouped and crosslinked reads originated from mRNAs, we classify LIN28 proteins as predominantly mRNA-binding proteins; snoRNAs or miRNAs represent minor targets in comparison. LIN28A and LIN28B proteins are similar to other mRBPs in that they bind thousands of $\mathrm{mRNAs}$ at defined sites and are present at high copy numbers per cell (Hafner et al. 2010b). Based on the overlap of binding sites, these two family members, which

$\begin{array}{ll}\begin{array}{l}\text { Let-7 } \\ \text { member }\end{array} & \text { Cistron } \\ -7 a-2 & -100 /-7 a-2 /-125 b-1 \\ -7 c & -99 a /-7 c /-125 b-2 \\ -7 e & -99 b /-7 e /-125 a \\ -7 a-1 & -7 a-1 /-7 f-1 /-7 d \\ -7 f-2 & -7 f-2 /-98 \\ -7 a-3 & -7-a-3 /-7 b \\ -7 f-1 & -7 a-1 /-7 f-1 /-7 d \\ -98 & -7 f-2 /-98 \\ -7 b & -7 a-3 /-7 b \\ -7 d & -7 a-1 /-7 f-1 /-7 d \\ -7 g & -7 g \\ -7 i & -7 i\end{array}$

FIGURE 5. Sequence alignment of let-7 miRNA family members. ClustalW alignment of pre-let-7 miRNA family members. The mature miRNA and the miRNA* sequences are indicated in red and blue font, respectively. Guanosines interacting with the ZK-domains of LIN28 proteins in structural studies are highlighted in yellow, and uridines possibly contributing to LIN28 binding in the unpaired loop region of pre-let-7 miRNAs are highlighted in red. The number of sequence reads from a small RNA-sequencing experiment for HEK293 cells (see Supplemental Table 8, data set uninduced, replicate A) are indicated for each let-7 member. (\#) Sequence reads that were split between the three indistinguishable mature miRNAs let-7a-1, let7a-2, and let-7a-3 and between let-7f-1 and let-7f-2, respectively. Also indicated is the LIN28B-dependent regulation, expressed as the ratio of miRNA expression in HEK293 cells depleted of LIN28B compared with cells after induction of FLAG/HA-LIN28B (Fig. 4D; Supplemental Table 8). 
share 73\% amino acid identity across the CSD and ZK domains, act redundantly. The predominantly exonic location of binding sites and their broad distribution across CDS and 3' UTR of mRNAs resembles that of other cytoplasmic RBPs, such as EIF2C/AGO1-4, IGF2BP1-3, or PUM2 (Hafner et al. 2010b). The exonic binding pattern also mirrors the mainly cytoplasmic localization of LIN28 proteins in HEK293 cells or other cell types (Guo et al. 2006; Polesskaya et al. 2007). The distribution of binding sites across mRNAs is also consistent with two recent studies using HiTSCLIP for LIN28A in HEK293, human, and murine embryonic stem cell lines (Cho et al. 2012; Wilbert et al. 2012). Furthermore, we observed some accumulation of LIN28B in the nucleolus as well as crosslinking of LIN28A and LIN28B to snoRNA precursors (Supplemental Table 2); nucleolar signals for LIN28B were previously noted (Polesskaya et al. 2007; Piskounova et al. 2011). However, we did not confirm a recent report of predominantly nuclear localization of LIN28B in HEK293 (Piskounova et al. 2011).

\section{LIN28 proteins share characteristics with other CSD-containing RBPs}

CSD domains are known to bind poly-pyrimidine containing ssRNA (Phadtare and Inouye 1999; Max et al. 2006, 2007; Nam et al. 2011; Mayr et al. 2012). Recent structural studies indicate that the ZKD mediates LIN28 interaction with guanosines downstream from the CSD-binding region (Nam et al. 2011). The RNA-binding sites for LIN28 proteins contained uridine-rich sequences and were comparatively G-rich with over $15 \%$ G. We did not observe a specific order of uridine-rich regions and guanosine residues, consistent with strong independent interaction of the CSD and the ZKD with RNA seen in our biochemical analysis. Motif analysis of binding sites was not able to recognize the contribution of isolated $\mathrm{G}$ residues to binding, but still captured the uridine-rich regions as AYYNY. We saw no significant enrichment for GGAGY, which was recently found in $28 \%$ of HiTS-CLIP binding sites for LIN28A, with no report of the importance of the uridine-rich element identified in the present study (Wilbert et al. 2012).

Beside LIN28A and LIN28B, the human genome encodes other CSD-containing proteins, YBX1 and YBX2, CSDA, CARHSP1, CCAR1, CSDC2, and CSDE1, none of which contain the additional ZKD characterizing LIN28 proteins. YBX1 is the best-characterized CSD protein (Davydova et al. 1997). It is similar to LIN28 proteins in that it is expressed at high copy numbers, interacts with pyrimidinerich RNAs, and binds mRNAs, as suggested by it localization within mRNP-containing cytoplasmic granules, including stress granules and P-bodies (Polesskaya et al. 2007). YBX1 was also found to modulate mRNA target stability and translation and is implicated in mRNP remodeling as it formed higher-order mRNP structures in vitro, depending on the stoichiometry of RNA and protein (Skabkin et al. 2004).
With the exception of CSDC2, which binds histone mRNA $3^{\prime}$ ends in the nucleus, all other CSD-proteins are also predominantly cytoplasmic, yet their biochemical properties as well as their cellular function remain poorly characterized.

LIN28 proteins prefer ssRNA targets, yet are able to recognize binding sites predicted to reside in stable secondary structures, as found in our and a related study using HiTS-CLIP to characterize LIN28A in mouse embryonic stem cells (Cho et al. 2012). It is therefore tempting to speculate that LIN28 proteins may influence RNA secondary structure in a chaperone-like function (Semrad 2011), and may thereby regulate the association or dissociation of other cellular mRBPs and contribute to remodeling of RNPs in the cytoplasm.

\section{LIN28 protein binding mildly stabilizes target mRNAs}

Quantification of mRNA levels indicated that LIN28 proteins are weak positive regulators of target mRNA stability, on average a $\sim 1 \%$ increase in stability across all targets, or a $\sim 4 \%$ increase for a bin containing the top 500 targets. LIN28 regulatory effects were previously mainly attributed to the inhibition of miRNA let-7 processing; however, the positive regulation by LIN28 was independent of the presence of predicted miRNA let-7 target sites on the mRNAs (Zhu et al. 2011; Supplemental Fig. 8). A recent study of LIN28A targets based on HiTS-CLIP did not observe LIN28A-dependent target mRNA changes, despite their use of a similar cell system (Wilbert et al. 2012). Global protein abundance changes for $\sim 1700$ proteins expressed from LIN28-protein targeted mRNAs were too small to be captured, indicating that LIN28 proteins are not acting as translational regulators. More focused analysis of the top mRNA targets and their cognate protein changes only mirrored the subtle changes in mRNA levels. Tightly coupled changes of mRNA and protein abundance were previously seen in knockdown or inhibition of other RBPs and miRNPs modulating mRNA stability in a steady state (Baek et al. 2008; Selbach et al. 2008; Lebedeva et al. 2011; Schwanhausser et al. 2011).

Studies using luciferase-based reporter assays observed between 1.2- and 3.5-fold LIN28-protein-dependent increases for 14 candidate targets identified by RIP-RT-qPCR (Polesskaya et al. 2007; Xu and Huang 2009; Xu et al. 2009) or HiTS-CLIP (Wilbert et al. 2012), attributed to either increased translational efficiency or stabilization of reporter mRNAs upon LIN28 protein binding. The reported effects were much stronger than we observed in our sensitive assays simultaneously monitoring all targets and may be attributed to the transient and nonphysiologic nature of reporter-based assays, and controls and the lack of isolating and mutating or deleting the precise LIN28 protein-binding sites.

In agreement with a recent study (Wilbert et al. 2012), the most dramatic protein regulatory response upon LIN28B level modulation was on LIN28B itself, where we observed a fivefold increase in endogenous LIN28B protein upon a threefold overexpression of FLAG/HA-tagged LIN28B protein 
compared with endogenous protein with a concomitant 1.5fold increase in endogenous LIN28B mRNA stability. This revealed an unexpected feed-forward mechanism for maintaining a high level of LIN28 protein and supports the switch-like expression patterns of this protein family in early embryonic stages and some cancers.

As seen with many RBPs, uncovering a large number of RNA targets complicates the identification of singular genes contributing to specific physiologic function assigned to changes in expression of a regulator. Our data indicate that LIN28 may be coordinately regulating groups of proteins all involved in similar cellular processes. We find the strongest regulation among nuclear RBPs, with $>10 \%$ average increase in transcript levels, confirming a possible role in modulation of mRNA splicing patterns upon overexpression of LIN28A (Wilbert et al. 2012). In support of reports of LIN28-mediated histone regulation by targeting $\mathrm{H} 2 \mathrm{~A}$ (Xu and Huang 2009) we further detected LIN28 RNA-binding sites in the linker histone H1FX, seven variants of the core histone $\mathrm{H} 2$, as well as histone $\mathrm{H} 4 \mathrm{H}$. Similarly, we significantly expanded the targets of LIN28 contributing to cell cycle regulation (Xu et al. 2009; Li et al. 2012) to now include 236 genes annotated as cell cycle related in the GO (Huang et al. 2009a,b) and KEGG (Ogata et al. 1999) databases, with CCND1/2, CCNB1, and CDK1/2 among the top targets (Supplemental Table 6). Another group of genes affected by LIN28 perturbation belong to the insulin-PI3K-mTOR signaling pathway (Zhu et al. 2011), previously thought to be indirectly regulated by the inhibition of miRNA let-7 processing. We found that LIN28 proteins bound directly to mRNAs of the insulin and IGF receptors, as well as of the downstream components IRS2/4 and AKT1-3. The type-2 diabetes associated genes IGF2BP1 to IGF2BP3 and HMGA2 were also among the direct targets and further support a more direct regulation of the insulin-PI3K-mTOR signaling pathway.

\section{LIN28B protein regulates mature let-7 member abundance in a loop-sequence-dependent manner}

PAR-CLIP in HEK293 cells provided some, albeit difficult to score, evidence for crosslinking of LIN28 proteins to mature or pre-let-7 in vivo. At the same time, we observed a wide range of sequence-dependent regulation of 1.2 - to 25 -fold when comparing let-7 levels upon knockdown and overexpression of LIN28B. The miRNA regulatory effects were post-transcriptional, since miR-99, miR-100, and miR-125 family members cistronically expressed with some unique let-7 members were unaffected by knockdown or overexpression of LIN28B. The simplest model explaining this regulation is sequence-dependent competition of LIN28B protein with miRNA biogenesis factors such as DICER1 protein, leading to degradation of pre-let-7 miRNAs, rather than their processing into mature miRNAs and assembly into RNA silencing complexes (Meister and Tuschl 2004; Kim et al. 2009; Thornton and Gregory 2012). While it is also conceiv- able that LIN28 proteins may influence let-7 levels indirectly via other RBPs identified as the top group of targets in this study, e.g., KHSRP (Trabucchi et al. 2009), their small changes in abundance are unlikely to trigger the larger relative changes in abundance observed for some of the let-7 members.

The small effect of LIN28 misexpression on let-7a compared with the other let-7 members in Flp-In HEK293 cells was noticed previously (Wilbert et al. 2012) and contrasts with other studies reporting that all let-7 family members respond upon overexpression of LIN28 proteins in MDAMB231, T47D, HEK293T, P493-6, NIH-3T3, as well as P19, J1, and neuronal stem cells (Heo et al. 2008, 2009; Newman et al. 2008; Rybak et al. 2008; Chang et al. 2009; Piskounova et al. 2011). Interestingly, let-7a-1 to let-7a-3 and also let-7c, let-7e, and let-7f-2, which exhibit smaller regulatory response upon LIN28 misexpression, also differ from the rest of the let-7 family by a shorter loop comprising only few uridines, representing a poor CSD RRE (Supplemental Fig. 9). It is tempting to speculate that these let-7 precursors have reduced affinity toward LIN28 proteins or are less efficiently recognized, and therefore compete more efficiently for DICER1 and/or other miRNA biogenesis factors. Considering competition between miRNA biogenesis and LIN28 protein binding, the discrepancies between various studies with respect to let-7 member responses may be due to their variable abundance in the experimental systems (Supplemental Fig. 9), e.g., plasmid-based overexpression (Heo et al. 2008) may yield higher LIN28 protein levels than expression from a Flp-In locus, as in the case of our and a related study (Wilbert et al. 2012).

In summary, we showed that LIN28 proteins bind thousands of protein-coding transcripts at distinct sites, albeit with small individual regulatory effects. The most distinct regulatory feature relating to LIN28 function in maintenance of stem cell properties is its own feed-forward regulation to facilitate high-level LIN28 protein expression, which contributes to the appearance of its switch-like expression pattern in development. Bioinformatic as well as detailed biochemical analysis demonstrated binding of LIN28 proteins to singlestranded RNAs with spatially separated uridine-rich elements and isolated guanosines by its two distinct RNA-binding domains with an ability to disrupt double-stranded regions comprising these RREs. This suggests a possible role for LIN28 proteins in mRNP remodeling, which may include responses to temperature changes (Shamovsky et al. 2006) or stress (Buchan et al. 2011).

\section{MATERIALS AND METHODS}

\section{Cell culture}

HEK293 cells expressing FLAG/HA-tagged LIN28A and LIN28B were prepared as described (Landthaler et al. 2008; Spitzer et al. 2011). Cells were maintained in DMEM containing 10\% FBS, $2 \mathrm{mM}$ glutamine, $15 \mu \mathrm{g} / \mathrm{mL}$ blasticidin, and $100 \mu \mathrm{g} / \mathrm{mL}$ hygromycin. 
FLAG/HA-LIN28A or LIN28B expression was induced by addition of $1 \mu \mathrm{g} / \mathrm{mL}$ doxycycline to the cell medium for at least $16 \mathrm{~h}$ prior to harvesting.

\section{Cellular fractionation}

Cytoplasmic and nuclear extracts of FLAG/HA-LIN28A or LIN28B expressing cells were generated according to Dignam (Dignam et al. 1983). Briefly, cells from one $15-\mathrm{cm}$ plate were trypsinized, collected by centrifugation at $500 \mathrm{~g}$ at $4^{\circ} \mathrm{C}$, washed with PBS, resuspended in PBS, and counted. Cells were pelleted again and resuspended in $5 \mathrm{~mL}$ of ice-cold buffer A (10 mM HEPES at pH 7.9, $1.5 \mathrm{mM} \mathrm{MgCl}_{2}$, $10 \mathrm{mM} \mathrm{KCl}, 0.5 \mathrm{mM} \mathrm{DTT}$, and one tablet of complete protease inhibitor [Roche] per $40 \mathrm{~mL}$ solution). Cells were disrupted using a 7$\mathrm{mL}$ Dounce homogenizer (15 strokes with pestle B). Dounced cells were centrifuged at $228 \mathrm{~g}$ for $5 \mathrm{~min}$ at $4^{\circ} \mathrm{C}$ to pellet nuclei. A total of $4 \mathrm{~mL}$ of the supernatant was saved, representing the cytoplasmic fraction, and $1 \mathrm{~mL}$ of $5 \times$ RIPA buffer $(250 \mathrm{mM}$ Tris- $\mathrm{HCl}$ at $\mathrm{pH} 7.5$, $750 \mathrm{mM} \mathrm{NaCl}, 5 \% \mathrm{NP}-40,2.5 \%$ deoxycholate) was added to it. The nuclear pellet was taken up in $3 \mathrm{~mL}$ of sucrose buffer S1 $(0.25 \mathrm{M}$ sucrose, $10 \mathrm{mM} \mathrm{MgCl}_{2}$, and one tablet of Complete protease inhibitor [Roche] per $40 \mathrm{~mL}$ solution) and the solution was placed on top of a cushion of $3 \mathrm{~mL}$ sucrose buffer S3 (0.88 M sucrose, $0.5 \mathrm{mM}$ $\mathrm{MgCl}_{2}$, and protease inhibitors) and centrifuged at $1430 \mathrm{~g}$ for $5 \mathrm{~min}$ at $4^{\circ} \mathrm{C}$. The pelleted nuclei were taken up in $1 \times$ RIPA buffer, and sonicated using a microtip five times for $10 \mathrm{sec}$ on ice.

\section{Immunofluorescence}

HEK293 cells expressing FLAG/HA-tagged LIN28A and LIN28B cells were grown on Lab-Tek II Chamber slides and induced with $1 \mu \mathrm{g} / \mathrm{mL}$ doxycycline $24 \mathrm{~h}$ before fixation. Chamber slides were rinsed with PBS and cells were fixed in 4\% paraformaldehyde/PBS for $15 \mathrm{~min}$ at room temperature (RT). Slides were washed for 5 min with $50 \mathrm{mM} \mathrm{NH}_{4} \mathrm{Cl}$ in PBS and cells were permeabilized in PBS supplemented with $0.1 \%$ Triton-X for $5 \mathrm{~min}$. Slides were blocked with $5 \%$ normal goat serum in PBS for $30 \mathrm{~min}$ at RT and subsequently incubated for $1 \mathrm{~h}$ at RT with anti-HA antibody solution (Sigma-Aldrich, H3663, 1:1000 in 5\% normal goat serum in PBS). Chamber slides were washed three times by $10 \mathrm{~min}$ incubation in PBS at RT, and were subsequently incubated for $1 \mathrm{~h}$ with a solution of Hoechst stain (1:1000) and Alexa Fluor 546 goat anti-mouse $\operatorname{IgG}(\mathrm{H}+\mathrm{L})(1: 500$ in $5 \%$ normal goat serum in PBS). Chamber slides were washed again three times using PBS and a 10-min incubation at room temperature and disassembled according to the manufacturer's instructions. Vectashield mounting medium (Vector laboratories Inc.) was used and slides were covered with microscope cover glass (Nr. 2, Fisher Scientific). Single-layer images were recorded on a Zeiss LSM-710 confocal microscope.

\section{siRNA knockdown of LIN28B}

A cocktail of three siRNA duplexes (3.3 nM final concentration for each duplex; siRNA_1: GGGAAGACAGGAAGCAGAAUU, UUC UGCUUCCUGUCUUCCCUU; siRNA_2: AGGGAAGACACUAC AGAAAUU, UUUCUGUAGUGUCUUCCCUUU; siRNA_3: GG AAGGAUUUAGAAGCCUAUU, UAGGCUUCUAAAUCCUUCC UU) was transfected in a 12-well format using Lipofectamine RNAiMAX (Invitrogen) as described by the manufacturer and incu- bated for $72 \mathrm{~h}$. Total RNA of transfected cells was extracted using TRIzol reagent according to the instructions of the manufacturer.

\section{mRNA microarray analysis}

RNA from knockdown experiments was further purified using the RNeasy purification kit (Qiagen). A total of $2 \mu \mathrm{g}$ of purified total RNA was used in the One-Cycle Eukaryotic Target Labeling Assay (Affymetrix) according to the manufacturer's protocol. Biotinylated cRNA targets were cleaned up, fragmented, and hybridized to Human Genome U133 Plus 2.0 Arrays (Affymetrix).

\section{SILAC-based protein quantification}

FLAG/HA-LIN28B-HEK293 cells were grown for at least seven passages prior to siRNA knockdown experiments in SILAC medium (DMEM (-Arg, -Lys) (Pierce) containing 10\% dialyzed fetal bovine serum (Pierce) supplemented with $84 \mathrm{mg} / \mathrm{L}^{13} \mathrm{C}_{6}^{15} \mathrm{~N}_{4} \mathrm{~L}$-arginine and $40 \mathrm{mg} / \mathrm{L}^{13} \mathrm{C}_{6}^{15} \mathrm{~N}_{2}$ L-lysine (Pierce) or the corresponding nonlabeled amino acids, respectively) (see Supplemental Fig. 6 for scheme). siRNA knockdown in heavy isotope-labeled cells or FLAG/HALIN28B expression in standard isotope-labeled cells was performed in $10-\mathrm{cm}$ plates for $72 \mathrm{~h}$ as described above. As biological replicates, the experiments were also performed using switched isotope labels. Cells were lysed using $2 \mathrm{~mL}$ SDS loading buffer (10\% glycerol (v/v), 50 mM Tris- $\mathrm{HCl}$ (pH 6.8), 2 mM EDTA, 2\% SDS (w/v), 100 mM DTT, $0.1 \%$ bromophenol blue), and LIN28B overexpression or knockdown was confirmed by immunoblotting. Protein expression was normalized by immunoblotting for TUBB and lysates from heavy and light isotope-labeled cells combined. A total of $50 \mu \mathrm{L}$ of the combined lysates were fractionated on a $4 \%-12 \%$ SDS-polyacrylamide gradient gel and the gel was stained using Colloidal blue (Invitrogen) according to the manufacturer's instruction. The gel lanes were divided into 12 equally sized slices and prepared for LC-MS according to the protocol published by Ong and Mann (2006). LC-MS/MS spectra were recorded on a Velos Orbitrap and raw files were processed using MaxQuant (Cox and Mann 2008) (version 1.0.11.5) and searched with the Mascot search engine (version 2.2.04, Matrix Science) against the IPI human v3.37 protein database.

\section{Small RNA cDNA sequencing}

Two micrograms of total RNA from siRNA-treated cells, mocktransfected cells, and cells induced to express FLAG/HA-LIN28B for $72 \mathrm{~h}$ were converted into small RNA cDNA libraries as previously described (Hafner et al. 2008, 2011) using the following barcoded $3^{\prime}$ adapters: LIN28B knockdown replicate 1: TCCACTCGTATG CCGTCTTCTGCTTG; LIN28B knockdown replicate 2: TCG ATTCGTATGCCGTCTTCTGCTTG; mock replicate 1: TCACTT CGTATGCCGTCTTCTGCTTG; mock replicate 2: TCCGTTCGT ATGCCGTCTTCTGCTTG; FLAG/HA-LIN28B induced replicate 1: TCATCTCGTATGCCGTCTTCTGCTTG; FLAG/HA-LIN28B induced replicate 2: TCCTATCGTATGCCGTCTTCTGCTTG.

\section{PAR-CLIP}

PAR-CLIP cDNA libraries were generated as reported previously (Hafner et al. 2010a,b). Briefly, $100 \times 10^{6}$ cells were cultured in 
medium supplemented with $100 \mu \mathrm{M} 4 \mathrm{SU}$ and $1 \mathrm{mM}$ doxycycline for $16 \mathrm{~h}$ to induce FLAG/HA-LIN28A or LIN28B expression. Next, cells were washed with PBS and irradiated with $0.15 \mathrm{~mJ} / \mathrm{cm}^{2} 365 \mathrm{~nm} \mathrm{UV}$ light in a Stratalinker 2400 to crosslink RNA to RBPs. Cells were harvested and lysed in the equivalent of three cell pellet volumes of NP40 lysis buffer. The cleared cell lysates were treated with $1 \mathrm{U} /$ $\mu \mathrm{L}$ RNase T1 (Fermentas). LIN28 proteins were immunoprecipitated with monoclonal anti-FLAG antibodies (M2, Sigma) bound to Protein G Dynabeads ( $0.25 \mathrm{mg}$ antibody per milliliter of beads, $10 \mu \mathrm{L}$ bead suspension per milliliter of cell lysate). The beads were taken up in one original bead suspension volume $(10 \mu \mathrm{L}$ bead suspension per milliliter of lysate), and RNA residing in the immunoprecipitate was further trimmed with $100 \mathrm{U} / \mathrm{mL}$ RNase T1. Beads were washed in lysis buffer and resuspended in one bead volume of dephosphorylation buffer. RNA was dephosphorylated and radioactively labeled with $\left[\gamma^{-32} \mathrm{P}\right] \mathrm{ATP}$. The protein-RNA complexes were separated by SDS-PAGE, and RNA-protein complexes visualized by autoradiography. The radioactive bands migrating at $\sim 30$ and 36 $\mathrm{kDa}$, respectively, were recovered and the protein-RNA complex was electroeluted from the gel. The protein was removed by digestion in proteinase $\mathrm{K}$ buffer ( $50 \mathrm{mM}$ Tris- $\mathrm{HCl}$ at $\mathrm{pH} 7.5,75 \mathrm{mM}$ $\mathrm{NaCl}, 6.25 \mathrm{mM}$ EDTA, $1 \%$ SDS) with $0.2 \mathrm{mg} / \mathrm{mL}$ proteinase $\mathrm{K}$ (Roche). Note that proteinase $\mathrm{K}$ treatment in PAR-CLIP experiments needs to be stringent for complete removal of peptides at the crosslinking site to facilitate read-through during reverse transcription. To ensure maximal activity of proteinase $\mathrm{K}$, stock solution of $20 \mathrm{mg} / \mathrm{mL}$ proteinase $\mathrm{K}$ in water was always freshly prepared from lyophilized powder. Thereafter, the RNA was recovered by acidic phenol/chloroform extraction and ethanol precipitation. The recovered RNA was converted into a cDNA library as described before (Hafner et al. 2008) and Illumina sequenced. Processed reads were aligned to the reference genome (GRCh37/ hg19) by the Bowtie algorithm (0.12.7), allowing for one alignment error (mutation, insertion, deletion). For each read, only unique mapping was allowed. After the conversion subtraction, reads that mapped to only one genomic location were retained for downstream analysis. For each library, PARalyzer was used to identify binding sites as described previously (Corcoran et al. 2011). See LIN28.ini file at rnaworld.rockefeller.edu/lin28 for details about exact parameters. PARalyzer-derived groups were annotated using an in-house software annotator, utilizing annotation data from the following sources.

1. Protein-coding transcript, lincRNA, misc_RNA, Mt_rRNA, Mt_tRNA, rRNA, snoRNA, and snRNA annotation were downloaded from biomart/Ensembl version GRCh37 (http://jun2011. archive.ensembl.org/biomart/martview).

2. Repetitive element annotation was downloaded from the RepeatMasker track of UCSC genome table browser (http:// genome.ucsc.edu/). Repeat elements of the class rRNA, snRNA, and tRNA were combined with Ensembl annotation for those categories described above.

3. piRNA annotation was downloaded from functional RNAdb version 3.4 (http://www.ncrna.org/frnadb/files/hg18_gtf.zip) and converted to hg19 using the liftOver utility.

4. miRNA annotation was downloaded from miRBase Sequence version 17 (http://www.mirbase.org/). Binding sites overlapping multiple annotation categories were assigned a single annotation according to the LIN28.yaml file available at rnaworld.rockefeller .edu/lin28 (higher number given more priority).

\section{Recombinant protein purification}

For bacterial overexpression, LIN28A clones were PCR-amplified from plasmid DNA from image clone 7467453 (The I.M.A.G.E. Consortium) and LIN28B clones were obtained from cDNA prepared from HEK293 (LIN28B) using primers containing BamHI and NotI restriction endonuclease recognition sites (LIN28A: AATCTAGGATCCATGGGCTCCGTGTCCAACCAG, TAAATCTT GCGGCCGCTCAATTCTGTGCCTCCGGGAG; LIN28B: AATCT AGGATCCATGGCCGAAGGCGGGGCTA, TAAATCTTGCGGCC GCTTATGTCTTTTTCCTTTTTTGAACTG). The PCR products were digested using BamHI and NotI, subcloned into a pET28based vector (EMD Biosciences) and transformed into E. coli BL21 (DE3) cells cotransfected with RIL codon plus plasmid. Cells were grown at $37^{\circ} \mathrm{C}$ and induced with $1 \mathrm{mM}$ IPTG at an $\mathrm{OD}_{600}$ of 0.8 , upon which the temperature was decreased to $25^{\circ} \mathrm{C}$, and growth was continued overnight. Cells were harvested by centrifugation at $9000 \mathrm{~g}$, lysed in $20 \mathrm{mM}$ Tris- $\mathrm{HCl}$ ( $\mathrm{pH} 7.5), 1 \mathrm{M} \mathrm{NaCl}, 5 \mathrm{mM}$ imidazole, and 1 mM DTT using an EmulsiFlex C5 homogenizer (Avestin), and recombinant protein was bound to a 5 -mL TALON column via its $\mathrm{N}$-terminal $\mathrm{His}_{6}$ tag. The protein was eluted using an imidazole gradient (5-250 $\mathrm{mM}$ ) over five column volumes, dialyzed against buffer containing $300 \mathrm{mM} \mathrm{NaCl}$, and the tag was proteolytically removed by thrombin-cleavage using a 1:40 ratio of LIN28 to thrombin. The cleaved protein was subjected to gel-filtration chromatography using a Superdex-75 10/30 column in $20 \mathrm{mM}$ Tris-HC l ( $\mathrm{pH}$ 7.5), $300 \mathrm{mM} \mathrm{NaCl}, 1 \mathrm{mM} \mathrm{DTT}$, and LIN28 protein containing fractions were concentrated to a final concentration of $50 \mu \mathrm{M}$ using Ultracell centrifugal filters (Millipore) and flash-frozen in liquid nitrogen.

\section{Gel-shift experiments}

Oligonucleotides were labeled with $\left[\gamma^{32} \mathrm{P}\right] \mathrm{ATP}$ and T4 polynucleotide kinase using standard conditions. The radiolabeled oligonucleotide concentration was $<4 \mathrm{nM}$ in all experiments, while the protein concentration was adjusted to $0 \mathrm{nM}, 10 \mathrm{nM}, 100 \mathrm{nM}$, and $1000 \mathrm{nM}$. In case of RNA duplex titrations (Fig. 2C), only one strand of each duplex strand was radiolabeled, (e.g., $(\mathrm{GU})_{9}$ in $\left.(\mathrm{GU}: \mathrm{AC})_{9}\right)$, and a $1.25 \times$ excess of unlabeled strand was used for duplex formation, prior to the addition of protein. Binding was performed in $10-\mu \mathrm{L}$ reactions using $50 \mathrm{mM}$ HEPES-KOH ( $\mathrm{pH} 7.0$ ), $150 \mathrm{mM} \mathrm{KCl,} 5 \mathrm{mM}$ $\mathrm{MgCl}_{2}, 10 \%$ glycerol as a buffer. Reactions were incubated at room temperature for $30 \mathrm{~min}$ and loaded on 0.8 -mm thick Tris-glycine (TG) $5 \%$ polyacryalmide gels with $15 \%$ stop gels (Protean Mini gel system, Bio Rad). Polyacrylamide gel electrophoresis was performed at $150 \mathrm{~V}$ in $1 \times \mathrm{TG}$ buffer at room temperature. OrangeG dye was used as a length reference as it migrates at an apparent length of $\sim 20 \mathrm{nt}$. The sequences for the RNAs used for shift experiments are shown in Figures 2 and 3.

\section{DATA DEPOSITION}

The Gene Expression Omnibus (GEO) accession number for the sequencing and microarray data is GSE44616.

\section{SUPPLEMENTAL MATERIAL}

Supplemental material is available for this article. 


\section{COMPETING INTEREST STATEMENT}

T.T. is cofounder and scientific advisor to Alnylam Pharmaceuticals and Regulus Therapeutics.

\section{ACKNOWLEDGMENTS}

We thank M. Landthaler for preparation of the FLAG/HA-LIN28B destination vector and the establishment of the corresponding HEK293 cell line. We are grateful to S. Dewell and C. Zhao (Genomics Resource Center) for Illumina sequencing. K.M. was supported by the Deutsche Forschungsgemeinschaft and M.H. by a fellowship of the Charles H. Revson Foundation. T.T. is an HHMI investigator, and the study was further supported by a grant from the Starr Cancer Foundation and NIH.

Received September 23, 2012; accepted February 1, 2013.

\section{REFERENCES}

Ambros V, Horvitz HR. 1984. Heterochronic mutants of the nematode Caenorhabditis elegans. Science 226: 409-416.

Baek D, Villén J, Shin C, Camargo FD, Gygi SP, Bartel DP. 2008. The impact of microRNAs on protein output. Nature 455: 64-71.

Balzer E, Heine C, Jiang Q, Lee VM, Moss EG. 2010. LIN28 alters cell fate succession and acts independently of the let-7 microRNA during neurogliogenesis in vitro. Development 137: 891-900.

Buchan JR, Yoon J-H, Parker R. 2011. Stress-specific composition, assembly and kinetics of stress granules in Saccharomyces cerevisiae. J Cell Sci 124: 228-239.

Chang T-C, Zeitels LR, Hwang H-W, Chivukula RR, Wentzel EA, Dews M, Jung J, Gao P, Dang CV, Beer MA, et al. 2009. Lin-28B transactivation is necessary for Myc-mediated let-7 repression and proliferation. Proc Natl Acad Sci 106: 3384-3389.

Cho J, Chang H, Kwon SC, Kim B, Kim Y, Choe J, Ha M, Kim YK, Kim VN. 2012. LIN28A is a suppressor of ER-associated translation in embryonic stem cells. Cell 151: 765-777.

Corcoran DL, Georgiev S, Mukherjee N, Gottwein E, Skalsky RL, Keene JD, Ohler U. 2011. PARalyzer: Definition of RNA binding sites from PAR-CLIP short-read sequence data. Genome Biol 12: R79.

Cox J, Mann M. 2008. MaxQuant enables high peptide identification rates, individualized p.p.b.-range mass accuracies and proteomewide protein quantification. Nat Biotech 26: 1367-1372.

Davydova EK, Evdokimova VM, Ovchinnikov LP, Hershey JW. 1997. Overexpression in COS cells of p50, the major core protein associated with mRNA, results in translation inhibition. Nucleic Acids Res 25: 2911-2916.

De Guzman RN, Wu ZR, Stalling CC, Pappalardo L, Borer PN, Summers MF. 1998. Structure of the HIV-1 nucleocapsid protein bound to the SL3 $\Psi$-RNA recognition element. Science 279: 384-388.

Dignam JD, Lebovitz RM, Roeder RG. 1983. Accurate transcription initiation by RNA polymerase II in a soluble extract from isolated mammalian nuclei. Nucleic Acids Res 11: 1475-1489.

Guo Y, Chen Y, Ito H, Watanabe A, Ge X, Kodama T, Aburatani H. 2006. Identification and characterization of lin-28 homolog B (LIN28B) in human hepatocellular carcinoma. Gene 384: 51-61.

Hafner M, Landgraf P, Ludwig J, Rice A, Ojo T, Lin C, Holoch D, Lim C, Tuschl T. 2008. Identification of microRNAs and other small regulatory RNAs using cDNA library sequencing. Methods 44: 3-12.

Hafner M, Landthaler M, Burger L, Khorshid M, Hausser J, Berninger P, Rothballer A, Ascano M, Jungkamp A-C, Munschauer M, et al. 2010a. PAR-CliP - a method to identify transcriptome-wide the binding sites of RNA binding proteins. J Vis Exp doi: 10.3791/2034.
Hafner M, Landthaler M, Burger L, Khorshid M, Hausser J, Berninger P, Rothballer A, Ascano M, Jungkamp A-C, Munschauer M, et al. 2010b. Transcriptome-wide identification of RNA-binding protein and MicroRNA target sites by PAR-CLIP. Cell 141: 129-141.

Hafner M, Renwick N, Brown M, Mihailovic A, Holoch D, Lin C, Pena JTG, Nusbaum JD, Morozov P, Ludwig J, et al. 2011. RNA-ligase-dependent biases in miRNA representation in deep-sequenced small RNA cDNA libraries. RNA 17: 1697-1712.

Hagan JP, Piskounova E, Gregory RI. 2009. Lin28 recruits the TUTase Zcchc11 to inhibit let-7 maturation in mouse embryonic stem cells. Nat Struct Mol Biol 16: 1021-1025.

Heo I, Joo C, Cho J, Ha M, Han J, Kim VN. 2008. Lin28 mediates the terminal uridylation of let-7 precursor microRNA. Mol Cell 32: 276-284.

Heo I, Joo C, Kim Y-K, Ha M, Yoon M-J, Cho J, Yeom K-H, Han J, Kim VN. 2009. TUT4 in concert with Lin28 suppresses microRNA biogenesis through pre-microRNA uridylation. Cell 138: 696-708.

Hofacker IL. 2003. Vienna RNA secondary structure server. Nucleic Acids Res 31: 3429-3431.

Huang DW, Sherman BT, Lempicki RA. 2009a. Bioinformatics enrichment tools: Paths toward the comprehensive functional analysis of large gene lists. Nucleic Acids Res 37: 1-13.

Huang DW, Sherman BT, Lempicki RA. 2009b. Systematic and integrative analysis of large gene lists using DAVID bioinformatics resources. Nat Protoc 4: 44-57.

Iliopoulos D, Hirsch HA, Struhl K. 2009. An epigenetic switch involving NF- $\kappa$ B, Lin28, Let-7 MicroRNA, and IL6 links inflammation to cell transformation. Cell 139: 693-706.

Kim VN, Han J, Siomi MC. 2009. Biogenesis of small RNAs in animals. Nat Rev Mol Cell Biol 10: 126-139.

King CE, Wang L, Winograd R, Madison BB, Mongroo PS, Johnstone CN, Rustgi AK. 2011. LIN28B fosters colon cancer migration, invasion and transformation through let-7-dependent and -independent mechanisms. Oncogene 30: 4185-4193.

Kishore S, Jaskiewicz L, Burger L, Hausser J, Khorshid M, Zavolan M. 2011. A quantitative analysis of CLIP methods for identifying binding sites of RNA-binding proteins. Nat Methods 8: 559564.

Landthaler M, Gaidatzis D, Rothballer A, Chen PY, Soll SJ, Dinic L, Ojo T, Hafner M, Zavolan M, Tuschl T. 2008. Molecular characterization of human Argonaute-containing ribonucleoprotein complexes and their bound target mRNAs. RNA 14: 2580-2596.

Lebedeva S, Jens M, Theil K, Schwanhausser B, Selbach M, Landthaler M, Rajewsky N. 2011. Transcriptome-wide analysis of regulatory interactions of the RNA-binding protein HuR. Mol Cell 43: 340-352.

Lee Y, Jeon K, Lee J-T, Kim S, Kim VN. 2002. MicroRNA maturation: Stepwise processing and subcellular localization. EMBO $J$ 21: 4663-4670.

Lehrbach NJ, Armisen J, Lightfoot HL, Murfitt KJ, Bugaut A, Balasubramanian S, Miska EA. 2009. LIN-28 and the poly(U) polymerase PUP-2 regulate let-7 microRNA processing in Caenorhabditis elegans. Nat Struct Mol Biol 16: 1016-1020.

Lei X-X, Xu J, Ma W, Qiao C, Newman MA, Hammond SM, Huang Y. 2012. Determinants of mRNA recognition and translation regulation by Lin28. Nucleic Acids Res 40: 3574-3584.

Li N, Zhong X, Lin X, Guo J, Zou L, Tanyi JL, Shao Z, Liang S, Wang LP, Hwang W-T, et al. 2012. Lin-28 homologue A (LIN28A) promotes cell cycle progression via regulation of cyclin-dependent kinase 2 (CDK2), cyclin D1 (CCND1), and cell division cycle 25 homolog A (CDC25A) expression in cancer. J Biol Chem 287: 17386-17397.

Max KEA, Zeeb M, Bienert R, Balbach J, Heinemann U. 2006. T-rich DNA single strands bind to a preformed site on the bacterial cold shock protein Bs-CspB. J Mol Biol 360: 702-714.

Max KEA, Wunderlich M, Roske Y, Schmid FX, Heinemann U. 2007. Optimized variants of the cold shock protein from in vitro selection: Structural basis of their high thermostability. J Mol Biol 369: 10871097. 
Mayr F, Schütz A, Döge N, Heinemann U. 2012. The Lin28 cold-shock domain remodels pre-let-7 microRNA. Nucleic Acids Res 40: 74927506.

Meister G, Tuschl T. 2004. Mechanisms of gene silencing by doublestranded RNA. Nature 431: 343-349.

Moss EG, Lee RC, Ambros VR. 1997. The cold shock domain protein LIN-28 controls developmental timing in C. elegans and is regulated by the lin-4 RNA. Cell 88: 637-646.

Nam Y, Chen C, Gregory RI, Chou JJ, Sliz P. 2011. Molecular basis for interaction of let-7 microRNAs with Lin28. Cell 147: 1080-1091.

Newman MA, Thomson JM, Hammond SM. 2008. Lin-28 interaction with the Let-7 precursor loop mediates regulated microRNA processing. RNA 14: 1539-1549.

Ng P, Keich U. 2008. GIMSAN: A Gibbs motif finder with significance analysis. Bioinformatics 24: 2256-2257.

Ogata H, Goto S, Sato K, Fujibuchi W, Bono H, Kanehisa M. 1999. KEGG: Kyoto Encyclopedia of Genes and Genomes. Nucleic Acids Res 27: 29-34.

Okita K, Matsumura Y, Sato Y, Okada A, Morizane A, Okamoto S, Hong H, Nakagawa M, Tanabe K, Tezuka K-I, et al. 2011. A more efficient method to generate integration-free human iPS cells. Nat Methods 8: 409-412.

Ong SE, Mann M. 2006. A practical recipe for stable isotope labeling by amino acids in cell culture (SILAC). Nat Protoc 1: 2650-2660.

Peng S, Chen L-L, Lei X-X, Yang L, Lin H, Carmichael GG, Huang Y. 2011. Genome-wide studies reveal that Lin 28 enhances the translation of genes important for growth and survival of human embryonic stem cells. Stem Cells 29: 496-504.

Phadtare S, Inouye M. 1999. Sequence-selective interactions with RNA by CspB, CspC and CspE, members of the CspA family of Escherichia coli. Mol Microbiol 33: 1004-1014.

Piskounova E, Viswanathan SR, Janas M, LaPierre RJ, Daley GQ, Sliz P, Gregory RI. 2008. Determinants of MicroRNA processing inhibition by the developmentally regulated RNA-binding protein Lin28. J Biol Chem 283: $21310-21314$.

Piskounova E, Polytarchou C, Thornton JE, LaPierre RJ, Pothoulakis C, Hagan JP, Iliopoulos D, Gregory RI. 2011. Lin28A and Lin28B inhibit let-7 MicroRNA biogenesis by distinct mechanisms. Cell 147: 1066-1079.

Polesskaya A, Cuvellier S, Naguibneva I, Duquet A, Moss EG, HarelBellan A. 2007. Lin-28 binds IGF-2 mRNA and participates in skeletal myogenesis by increasing translation efficiency. Genes Dev 21: $1125-1138$

Rosner M, Hengstschläger M. 2008. Cytoplasmic and nuclear distribution of the protein complexes mTORC1 and mTORC2: Rapamycin triggers dephosphorylation and delocalization of the mTORC2 components rictor and sin1. Hum Mol Genet 17: 2934-2948.

Rybak A, Fuchs H, Smirnova L, Brandt C, Pohl EE, Nitsch R, Wulczyn FG. 2008. A feedback loop comprising lin-28 and let-7 controls pre-let-7 maturation during neural stem-cell commitment. Nat Cell Biol 10: 987-993.

Schwanhausser B, Busse D, Li N, Dittmar G, Schuchhardt J, Wolf J, Chen W, Selbach M. 2011. Global quantification of mammalian gene expression control. Nature 473: 337-342.

Selbach M, Schwanhausser B, Thierfelder N, Fang Z, Khanin R, Rajewsky N. 2008. Widespread changes in protein synthesis induced by microRNAs. Nature 455: 58-63.
Semrad K. 2011. Proteins with RNA chaperone activity: A world of diverse proteins with a common task-impediment of RNA misfolding. Biochem Res Int 2011: 532908.

Shamovsky I, Ivannikov M, Kandel ES, Gershon D, Nudler E. 2006. RNA-mediated response to heat shock in mammalian cells. Nature 440: 556-560.

Skabkin MA, Kiselyova OI, Chernov KG, Sorokin AV, Dubrovin EV, Yaminsky IV, Vasiliev VD, Ovchinnikov LP. 2004. Structural organization of mRNA complexes with major core mRNP protein YB-1. Nucleic Acids Res 32: 5621-5635.

Spitzer J, Landthaler M, Tuschl T. 2011. Rapid creation of stable mammalian cell lines for regulated expression of proteins using the Gateway Recombination Cloning Technology and Flp-In T-REx lines. In Methods in Enzymology and Methods in Cell BiologyMethods Navigator (ed. Lorsch J, Abelson J). Elsevier, Amsterdam.

Thornton JE, Gregory RI. 2012. How does Lin28 let-7 control development and disease? Trends Cell Biol 22: 474-482.

Trabucchi M, Briata P, Garcia-Mayoral M, Haase AD, Filipowicz W, Ramos A, Gherzi R, Rosenfeld MG. 2009. The RNA-binding protein KSRP promotes the biogenesis of a subset of microRNAs. Nature 459: 1010-1014

Viswanathan SR, Daley GQ, Gregory RI. 2008. Selective blockade of MicroRNA processing by Lin28. Science 320: $97-100$.

West JA, Viswanathan SR, Yabuuchi A, Cunniff K, Takeuchi A, Park IH, Sero JE, Zhu H, Perez-Atayde A, Frazier AL, et al. 2009. A role for Lin 28 in primordial germ-cell development and germ-cell malignancy. Nature 460: 909-913.

Wilbert ML, Huelga SC, Kapeli K, Stark TJ, Liang TY, Chen SX, Yan BY, Nathanson JL, Hutt KR, Lovci MT, et al. 2012. LIN28 binds messenger RNAs at GGAGA motifs and regulates splicing factor abundance. Mol Cell 48: 195-206.

Xu B, Huang Y. 2009. Histone H2a mRNA interacts with Lin28 and contains a Lin28-dependent posttranscriptional regulatory element. Nucleic Acids Res 37: 4256-4263.

Xu B, Zhang K, Huang Y. 2009. Lin28 modulates cell growth and associates with a subset of cell cycle regulator mRNAs in mouse embryonic stem cells. RNA 15: 357-361.

Yang DH, Moss EG. 2003. Temporally regulated expression of Lin-28 in diverse tissues of the developing mouse. Gene Expr Patterns 3: 719-726.

Yang X, Lin X, Zhong X, Kaur S, Li N, Liang S, Lassus H, Wang L, Katsaros D, Montone K, et al. 2010. Double-negative feedback loop between reprogramming factor LIN28 and microRNA let-7 regulates aldehyde dehydrogenase 1-positive cancer stem cells. Cancer Res 70: 9463-9472.

Yu J, Vodyanik MA, Smuga-Otto K, Antosiewicz-Bourget J, Frane JL, Tian S, Nie J, Jonsdottir GA, Ruotti V, Stewart R, et al. 2007. Induced pluripotent stem cell lines derived from human somatic cells. Science 318: 1917-1920.

Zhu H, Shah S, Shyh-Chang N, Shinoda G, Einhorn WS, Viswanathan SR, Takeuchi A, Grasemann C, Rinn JL, Lopez MF, et al. 2010. Lin28a transgenic mice manifest size and puberty phenotypes identified in human genetic association studies. Nat Genet 42: 626-630.

Zhu H, Shyh-Chang N, Segrè AV, Shinoda G, Shah SP, Einhorn WS, Takeuchi A, Engreitz JM, Hagan JP, Kharas MG, et al. 2011. The Lin28/let-7 axis regulates glucose metabolism. Cell 147: 81-94. 

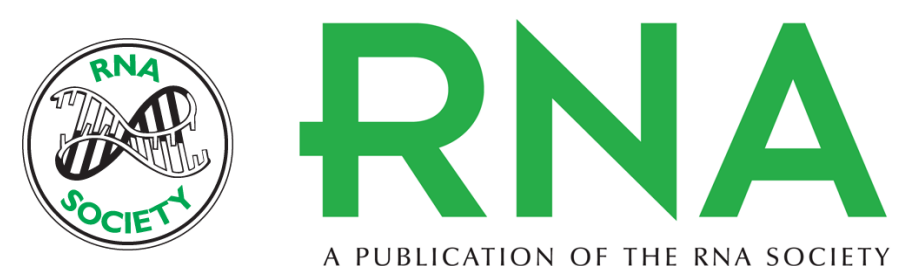

A PUBLICATION OF THE RNA SOCIETY

\section{Identification of mRNAs bound and regulated by human LIN28 proteins and molecular requirements for RNA recognition}

Markus Hafner, Klaas E.A. Max, Pradeep Bandaru, et al.

RNA 2013 19: 613-626 originally published online March 12, 2013

Access the most recent version at doi:10.1261/rna.036491.112

Supplemental
Material http://rnajournal.cshlp.org/content/suppl/2013/02/27/rna.036491.112.DC1

References This article cites 67 articles, 16 of which can be accessed free at:

http://rnajournal.cshlp.org/content/19/5/613.full.html\#ref-list-1

License

Email Alerting Receive free email alerts when new articles cite this article - sign up in the box at the Service top right corner of the article or click here.

To subscribe to RNA go to:

http://rnajournal.cshlp.org/subscriptions 